\title{
The mediums of dissemination of knowledge and illustration in neurosurgery: unraveling the evolution
}

\author{
Bharath Raju, MD, MCh, ${ }^{1}$ Fareed Jumah, MD, ${ }^{1}$ Vinayak Narayan, MD, ${ }^{1}$ Anika Sonig, BA, ${ }^{2}$ \\ Hai Sun, MD, ${ }^{1}$ and Anil Nanda, MD, MPH ${ }^{1}$ \\ 1Department of Neurosurgery, Rutgers-Robert Wood Johnson Medical School and University Hospital, New Brunswick, New \\ Jersey; and ${ }^{2}$ Rice University, Houston, Texas
}

\begin{abstract}
The earliest evidence of man's attempts in communicating ideas and emotions can be seen on cave walls and ceilings from the prehistoric era. Ingenuity, as well as the development of tools, allowed clay tablets to become the preferred method of documentation, then papyrus and eventually the codex. As civilizations advanced to develop structured systems of writing, knowledge became a power available to only those who were literate. As the search to understand the intricacies of the human brain moved forward, so did the demand for teaching the next generation of physicians. The different methods of distributing information were forced to advance, lest the civilization falls behind. Here, the authors present a historical perspective on the evolution of the mediums of illustration and knowledge dissemination through the lens of neurosurgery. They highlight how the medium of choice transitioned from primitive clay pots to cutting-edge virtual reality technology, aiding in the propagation of medical literature from generation to generation across the centuries.

https://thejns.org/doi/abs/10.3171/2020.7.JNS201053
\end{abstract}

KEYWORDS history; papyrus; codex; Vesalius; illustration; animation; virtual reality

$\mathrm{M}$ EDICAL literature and knowledge have been growing exponentially over the last decade. Technological advancement ushered in the era of big data and artificial intelligence. Technology has enabled the dissemination of information virtually, becoming accessible to all. However, this was not the situation even a few decades ago. It is crucial to understand how these technologies for dissemination of knowledge evolved, as it allows one to make more sense of the current world and allows us to exercise critical thinking.

Writing and illustration started as cave wall carvings and symbols on clay pots. The genesis of languages and alphabets led to the blossoming of a variety of mediums, including papyrus, parchment, and paper. But these were only accessible to a few literates and were considered a sign of power. Along with language, people realized the importance of illustrations in communicating knowledge. With the humanistic approach of the Renaissance, the content of books expanded, and the illustration of anatomy became a disruptive technology. The advent of printing technology and later photography made books and illustrations easily reproducible, allowing rapid circulation and access for many. The further technological revolution made three-dimensional (3D) viewing of anatomy possible, paving the way for virtual reality (VR) and simulations. Here, we investigate the history of the medium of illustrations and the dissemination of knowledge of anatomy and neuroanatomy. For better comprehension, we have divided the evolution into three stages: a pre-Renaissance era (before $1500 \mathrm{AD}$ ), from the Mesopotamian civilization up to the Italian Renaissance and the Age of Exploration, in which physical mediums dominated; an early modern era (after $1500 \mathrm{AD}$ ), from the beginning of the Renaissance up to the 19th century, during which there was a slow rise of technologies; and the contemporary era (1900 AD-present day), a period of dramatic increase in technology leading to virtual mediums.

\section{Physical Mediums of the Pre-Renaissance Era: Before 1500 AD \\ Clay Tablets and Stones}

Writing on clay or stone is the earliest known form of dissemination, dating back to the Mesopotamian civilization approximately 3000 years BC. The oldest known medical inscriptions written by an unknown Sumerian physician were excavated in the ruins of Nippur in modern-day Iraq. ${ }^{1}$ They were written in small cuneiform characters on a 5-inch-long quadrilateral tile of wet clay using a stylus, 


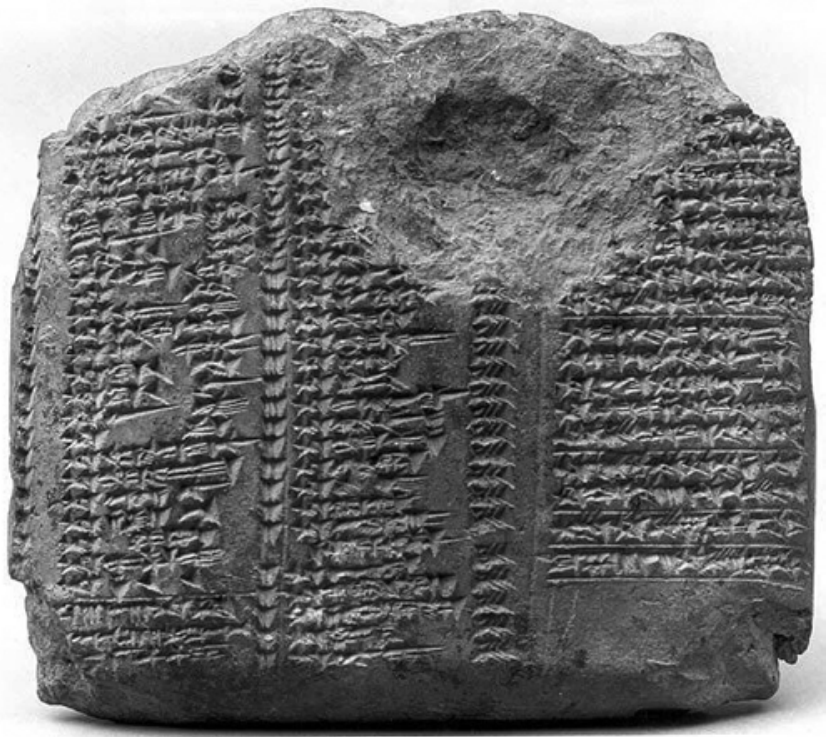

FIG. 1. Fragment of a clay tablet with cuneiform inscription describing a medical treatment. From https://www.metmuseum.org/art/collection/ search/321680. Public domain.

then baked and dried in the sun to make them durable. Long texts were inscribed on multiple tablets that were sequenced by a combination of numbers and unique characters (Fig. 1). As of now, more than 500,000 clay tablets have been recovered. ${ }^{2}$ Currently preserved in The British Museum, the Dying lioness from Nineveh relief, carved on alabaster stone, represents probably the oldest illustration of paraplegia dating back to 650 BC (Fig. 2). ${ }^{3,4}$ Following the introduction of Aramaic, one of the earliest alphabetic languages in human history, the use of clay tablets and

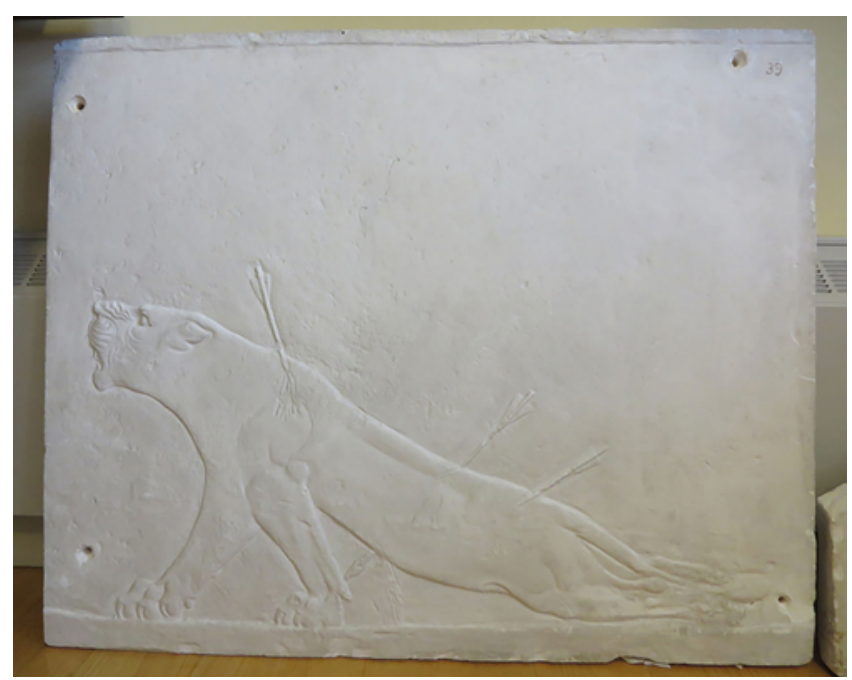

FIG. 2. The Dying lioness relief wall panel from Ashurbanipal's (650 BC) palace at Nineveh depicts a lioness dragging its hind limbs because of a spinal cord injury from arrows sticking in its back. This picture is a cast of the original relief preserved in The British Museum. Photography by Cornell University Library, Annetta Alexandridis, and Verity Platt. Reproduced with permission from Cornell University Library. Figure is available in color online only.

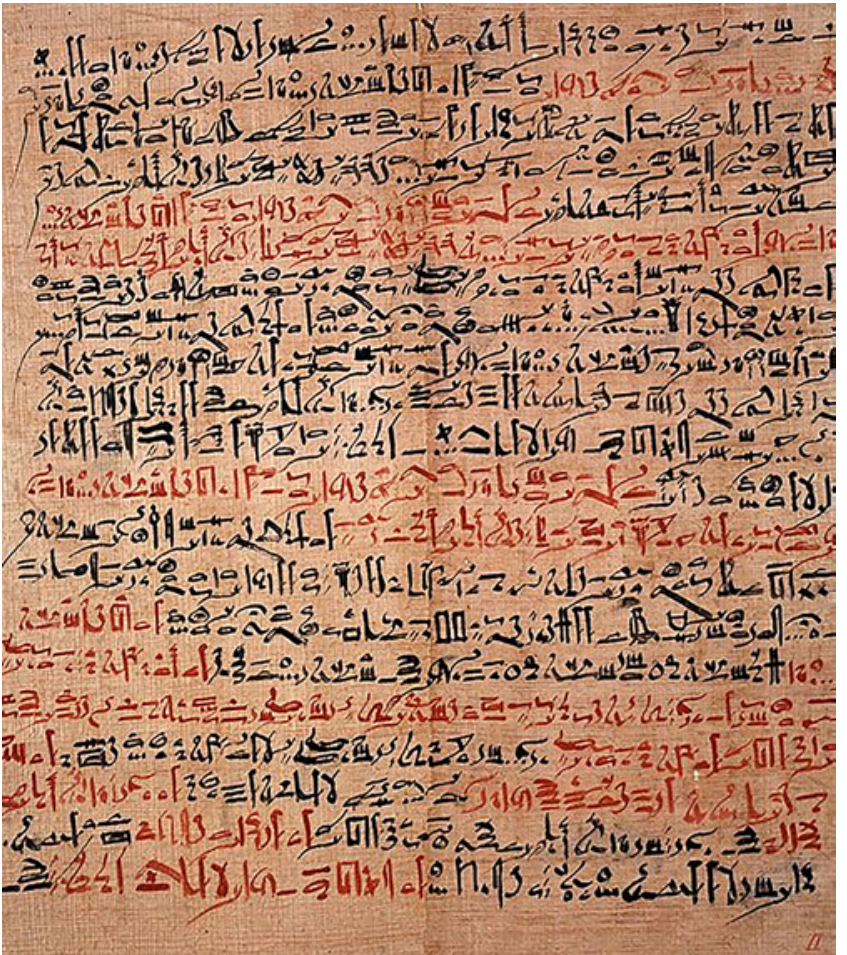

FIG. 3. The Edwin Smith Papyrus is the oldest surgical document describing the management of head injury. From https://en.wikipedia. org/wiki/Edwin_Smith_Papyrus. Public domain. Figure is available in color online only.

stone cuneiform writings dwindled, and by the 6th century $\mathrm{BC}$, papyrus became the predominant medium of illustration and knowledge dissemination. ${ }^{5}$

\section{Papyrus}

Ancient Egyptians were the first to use papyrus for writing and illustration as far back as $2500 \mathrm{BC}$, which continued into Roman Egypt (30 BC-640 AD). "Papyrus" is a Greek word originating from the Egyptian word "papuro" meaning "the royal." It was made from the plant Cyperus papyrus, a natural vegetation on the Nile Delta. The process of cultivation and production was expensive and needed skilled labor, which explains why it was exclusively under the control of the royal, or the pharaoh. ${ }^{5}$ As papyrus was expensive and limited, people would first practice on clay, wood, or stone before writing on it. Ancient Egyptian scribes, the select few who knew how to read and write at the time, carried wooden toolkits containing pens made of reed or bamboo stems and black and red paint cake. Red was used for the names of evil spirits or demons and for incantations, as the Egyptians believed magic was effective together with medicine, as evident in the Ebers Papyrus., 3

The Kahun Gynaecological Papyrus, Edwin Smith Papyrus (Fig. 3), and Ebers Papyrus are three important ancient medical texts whose original authors are unknown.? They were instead named after people who owned or donated them to museums, such as the German Egyptologist Georg Moritz Ebers (1837-1898). The Ebers Papyrus, written 3500 years ago, is the longest and most complete 
papyrus filled with spells and incantations to expel the "evils of disease," as well as herbal remedies for around 700 conditions including neurological disorders. The Edwin Smith Papyrus, a less magical and more structured papyrus, is the oldest surgical document addressing trauma management, likely written for surgeons in field hospitals. It describes the history, examination, diagnosis, treatment, and outcome of 48 cases, including head and spine injuries., 5 The magnificent survival of these papyri over thousands of years was in part due to Egypt's dry climate, which prevented decomposition, and the practice of entombing scientific texts over the dead as the Book of the Dead. ${ }^{3}$

The Greek physician Hippocrates (460-370 BC) was the first to write medical papyri free of spells and incantations. His ancient collection of around 60 manuscripts, known as the Hippocratic Corpus, contains various writings ranging from Hippocrates' personal scattered notes to detailed case descriptions such as epilepsy, which he called the "sacred disease." He is perhaps most well-known for authoring the ethical code, which we now know as the Hippocratic Oath, part of the Papyrus Oxyrhynchus (275 AD). ${ }^{8}$

\section{Codex}

Codex, which was introduced in the early Christian era, had marked a revolution in the dissemination of knowledge. It consisted of multiple sheets of papyrus (and later leather and vellum) bound together, where both sides could be used to scribe, and is essentially the predecessor of the modern-day book. Inspired by the design of the Roman wax tablets, which were reusable writing surfaces made of wax lined with a wooden frame, the codex was initially used for religious texts. ${ }^{3}$ It was a revolutionary change at the time, when a nation's cumulative wealth of codices became a sign of its power and prosperity. The Egyptians had been using leather for writing as early as $2450 \mathrm{BC}$, but it was not used regularly, as the papyrus was widely available at the time. At around 190 BC, a cold war erupted between Ptolemy V Epiphanes of Egypt and Eumenes II of Pergamon, Greece. Fearing the collections of codices in Pergamon might outstrip those of Alexandria, Ptolemy withheld the export of papyrus, which in turn motivated the Greeks to utilize leather/parchment as an alternative (Fig. 4). ${ }^{9}$ Unlike the more fragile papyrus, parchment was more flexible and durable, which enabled the production of codices with a greater number of sheets. Further finer processing and thinning of the parchment yielded vellum, which eventually replaced papyrus as the predominant medium of writing and dissemination. .,10 $^{3}$

The Library of Pergamon, arguably the most important library in the ancient world, had around 200,000 volumes and received many contributions in the form of codices from prominent anatomists and physicians such as Galen (129-216 AD), Herophilus (330-260 BC), Pedanius Dioscorides (40-90 AD), Erasistratus (304-250 BC), Rufus (70-110 AD), Soranus, and Aretaeus of Ephesus. By dictating to scribes, Galen produced more than 500 manuscripts and treatises, called the Galenic corpus, which included 20 medical references that no longer existed in the Egyptian civilization. ${ }^{11-13}$

After conquering the Greeks, the Romans confiscated

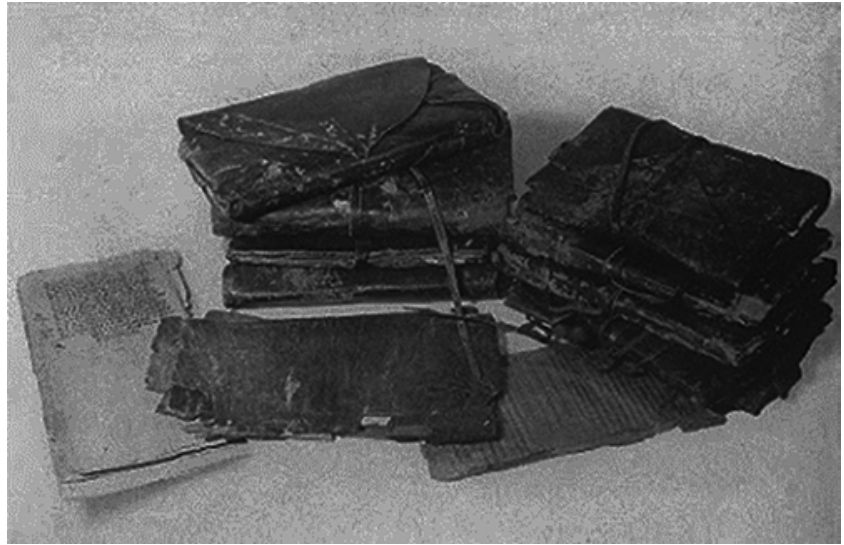

FIG. 4. Nag Hammadi codices made of parchment (leather), like the Galenic corpus. From http://thetextualmechanic.blogspot.com/2018/05/ galen-on-parchment-codex.html. Public domain.

the codices from the Greek libraries and enslaved their scribes to translate the texts into Latin, which explains why Roman literature is an imitation of the Greeks'. Later during the reign of the Byzantine Empire, the copying of codices by students ensured the survival of Greek literature, as did textual criticism and translations into Arabic and other languages. A chain of civil wars that eventually brought the Roman Empire to its knees resulted in the loss of most Greek and Roman manuscripts, with a few remnants ultimately finding refuge in religious abbeys and churches. None of the complete original manuscripts of the Greeks and Romans exist today. However, efforts of scholars like Aldo Manuzio (1456-1516 AD) helped to preserve Greek medical literature through compiling, editing, and printing the works of physicians such as Hippocrates, Aristotle, and Dioscorides. ${ }^{9,13}$

\section{Physical Mediums of the Early Modern Era: After 1500 AD \\ Books \\ Paper}

By the 14th century, the codex was made predominantly from paper. The advent of printing technology ushered in the era of the book, which is essentially a codex that is printed rather than handwritten. The Chinese used paper as early as 105 AD. Ts'ai Lun (48-121 AD), a Chinese inventor and politician, is credited with inventing paper by using the inner bark of a mulberry tree and bamboo fibers. ${ }^{10}$ Paper reached Europe from China through Arab traders. By the 14th century, manually operated paper mills were established in Europe, the first in Germany near Nuremberg. ${ }^{14}$ The Frenchman Louis-Nicolas Robert (1761-1828) fully mechanized the process of papermaking, which was later improved by John Dickinson..$^{10}$

\section{Print}

Printing underwent an important series of innovations, from the primitive surface printing techniques to our modern-day offset printing technology. Woodblock printing, also known as surface printing, was invented in Japan around $770 \mathrm{AD}$ and was key in the spread of Buddhism in 

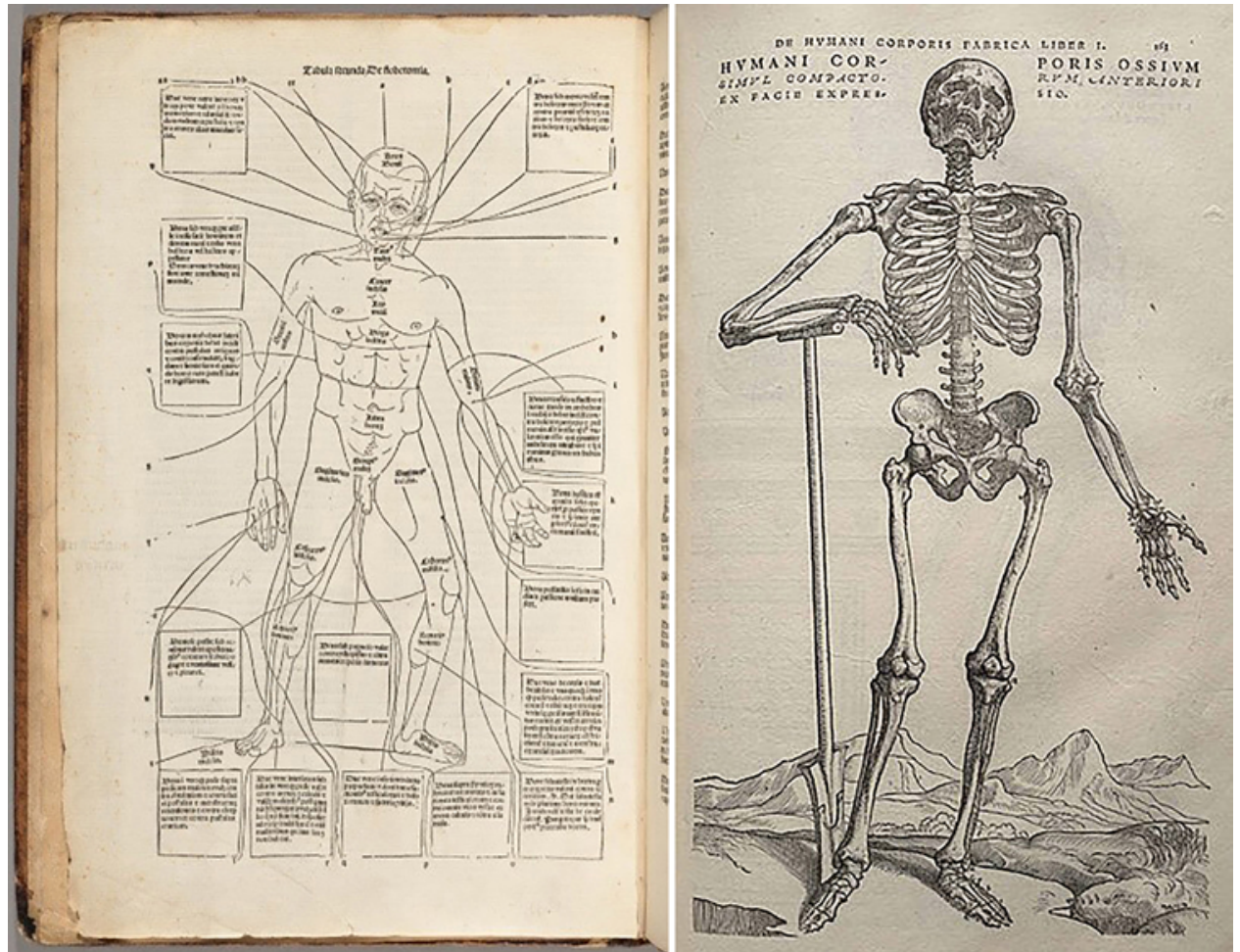

FIG. 5. Left: Johannes de Ketham used woodblock printing for the first time in his book Fasciculus Medicinae. From https://www. historyofinformation.com/image.php?id=3257. Public domain. Right: Woodblock-printed illustration of anatomy from De Humani Corporis Fabrica by Andreas Vesalius. From https://commons.wikimedia.org/w/index.php?curid=458936. Public domain. Figure is available in color online only.

Asia through the printing of religious prayers and literature..$^{15}$ The technique involved pasting hand-drawn images or text on a block of wood, then carving the excess wood around. The woodblock was then inked and pressed onto a sheet of paper to print the elevated markings. ${ }^{4,14}$

In 1491, anatomist Johannes de Ketham used woodblock printing for the first time in his book Fasciculus Medicinae to create six illustrations of "five-figure series" and anatomical fugitive sheets (Fig. 5 left). ${ }^{16,17}$ Jacopo Berengario da Carpi (1450-1530) was the first anatomist to print multidimensional pictures of anatomy with descriptions in his book Commentario Super Anatomia Mundini in 1521. ${ }^{18}$ Andreas Vesalius (1514-1564), the founder of modern anatomy and medicine, published a 7-volume series of books on human anatomy, De Humani Corporis Fabrica, in 1543 (Fig. 5 right). It was the first medical book to use a publication production team and contained 663 pages of printed text and $>400$ original images on 85 plates printed using woodcuts. ${ }^{19}$ These woodblocks, created by artists of the Venetian School in Italy, were transported to Switzerland to be used in printing by Johannes Oporinus (15071568), making him the first medical publisher in history. The third and seventh volumes of the series focused on the CNS. The first edition, dedicated to the Holy Roman Emperor Charles V, was silk bound and vellum paged and is the only hand-colored version of the book. ${ }^{3,20}$

A more advanced printing technique that followed woodcutting is intaglio, which used copper engravings instead of wood to create more durable, clearly defined prints. The next major leap in printing technology was around 1450, when Johannes Gutenberg (1400-1468 AD), a German blacksmith at the time, invented the printing press, which launched the printing revolution in Europe. He introduced the first mechanical movable typeface, which employs small metal letters fitted to a frame that is pressed against paper..$^{14}$ Over time, paper completely replaced vellum, and printed books replaced codex.

This rapid progress in printing resulted not only in the widespread publication of anatomical, medical, and surgical texts, but also in numerous feats of plagiarism. Flemish surgeon Thomas Geminus (1510-1562), in his book Compendiosa Totius Anatomie Delineatio, used copper engraving to plagiarize and reproduce 40 pictures of Vesalius' Fabrica. 15,21

In 1798, Alois Senefelder, of Munich, introduced lithography, a technique that exploits the property of oil and water immiscibility to print on paper from a stone or rubber surface. ${ }^{22}$ By the second part of the 19th century, lithography became the principal means of printing. During this time, there were numerous improvements to the process through the introduction of colored lithographs, commercial lithography, and offset printing. The latter method, in which an image is printed on a rubber cylinder and then transferred onto paper, became the most popular. ${ }^{22}$ In the modern era of medical illustration using lithography, Max Brödel (1870-1941) was a pioneer. Oftentimes known as the father of modern medical illustration, he contributed to neurosurgery by collaborating with Harvey Cushing and illustrating precise surgical anatomy from the surgeon's operative perspective. He is also credited with in- 


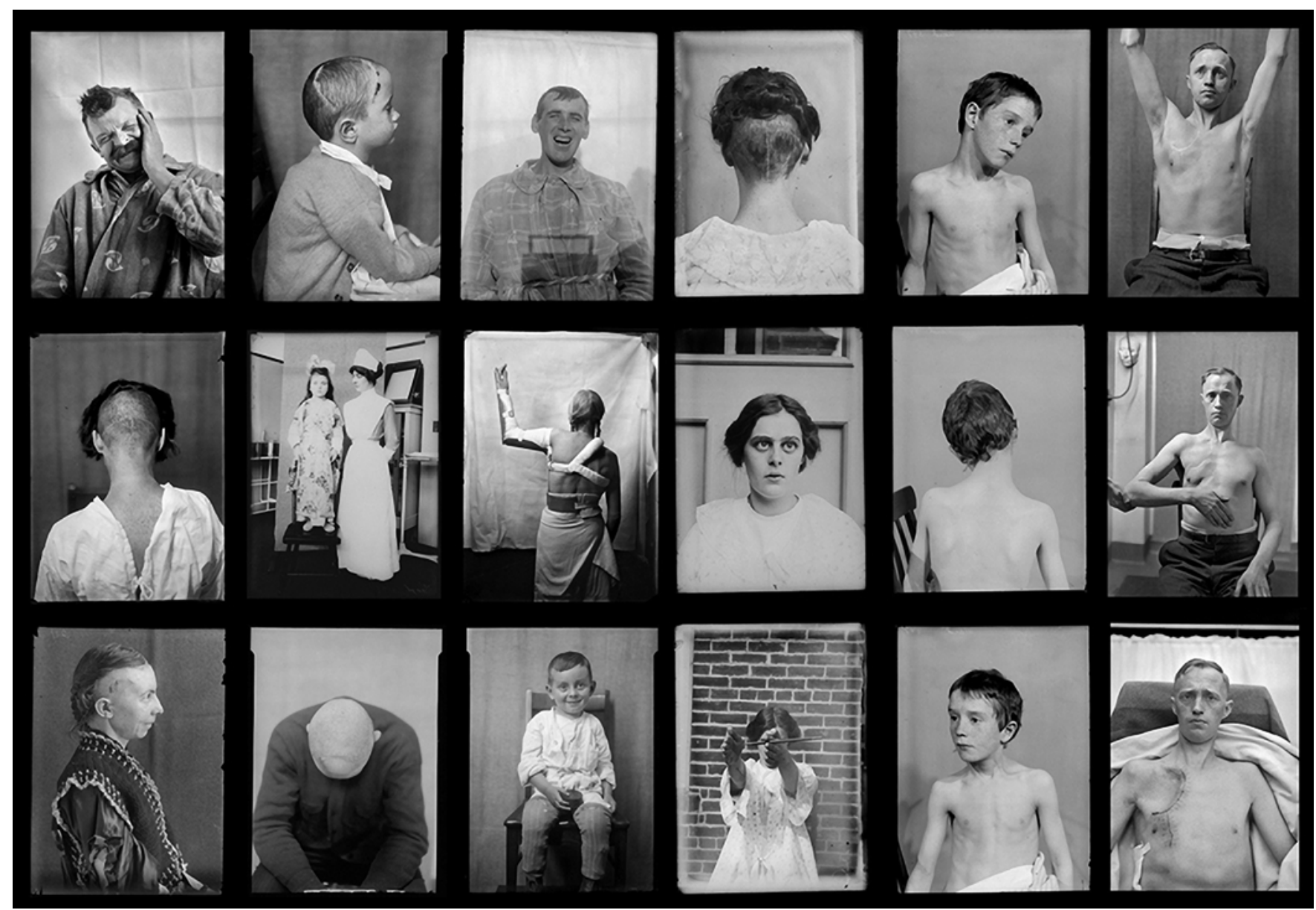

FIG. 6. Photographs of Cushing's patients with different neurosurgical conditions. From http://photos.yale.edu/directory/dir_single_ collection.php?collection_id=128. Photography by Terry Dagradi. Yale University, Harvey Cushing/John Hay Whitney Medical Library.

venting the "carbon dust" illustration technique. In 1911, Brödel started and directed the Department of Medical Illustration at the Johns Hopkins School of Medicine. ${ }^{23,24}$ Continuous improvements in digital printing technology are trying to replace offset printing.

\section{Anatomical Models}

Though it is outside the scope of this review, 3D models deserve brief mention here. These 3D models evolved as a medium of dissemination and learning, especially anatomy. They were created from metal, wax, clay, ivory, or paper and came in handy when medical students struggled to acquire and dissect cadavers within a day or two to avoid decomposition-given the absence of embalming at the time. Interested bibliophiles are advised to review papers written by Ballestriero and by Ortug and Yuzbasioglu on wax and papier-mâché models, respectively. ${ }^{25,26}$

\section{Photography}

Up until the advent of photography, creating medical images was highly dependent on artists. In 1826, Joseph Niépce (1765-1833) produced the first photograph using the prototype, the camera obscura. He, along with Louis Daguerre (1787-1851), improved the photographic process to create higher quality images, and the method was called the "daguerreotype process." However, reprinting was not possible using this technique until the introduction of negatives 20 years later. ${ }^{27}$ French physician and cytologist Alfred François Donné (1801-1878) employed this technique to study medical specimens. In 1844, Donné, along with photographer Jean Bernard Foucault, published the first photomicrograph of leukemia cells and platelets, demonstrating the scope of this instrument in medical practice. ${ }^{28,29}$ With further refinements and widespread use, photographing patients, procedures, and specimens became routine. Later in 1912, Harvey Cushing (18691939), the father of modern neurosurgery, built a registry of pathological brain specimens, microscopic slides, and photographic plates of his patients (Fig. 6). In 1979, years after Cushing's era, his registry was shifted to the subbasement of a student dormitory at Yale University. After 1994, collaborative efforts and funds restored the registry, currently displayed in The Cushing Center at Yale University. The collection contains over 10,000 films and glass plate negative photographs of brain specimens and of Cushing's patients during various stages of brain tumor management. ${ }^{30,31}$ Cushing's photographic collections essentially represent the evolution of modern neurosurgery from late 1800 to 1936. 


\section{Physical and Virtual Learning Mediums of the Contemporary Era: After 1900 AD \\ Surgical Motion Picture}

The introduction of the surgical motion picture in the early 20 th century gave life to medical images, revolutionizing the means of knowledge dissemination. The first surgical video on record was of Dr. Robert Fitzpatrick performing a cesarean section in 1915. In the following decades, a chain of innovations improved the process of filmmaking by incorporating color and audio into the surgical motion pictures. ${ }^{32}$ James Rudolph Jaeger (1895-1968) was the first neurosurgeon to produce and popularize the neurosurgical motion picture for teaching. In 1959, he established Rudolph Jaeger Productions, which produced 21 neurosurgical motion picture documentaries that were widely presented at scientific meetings and conventions at the time. ${ }^{33}$ Nowadays, the widespread use of high-definition cameras within surgical microscopes and endoscopes have made surgical videos a cornerstone of medical education.

\section{Digital Illustration, Animation, and 3D Printing}

Medical animation has facilitated the understanding of anatomy and the teaching of basic and advanced concepts of medicine and surgery. It was debuted in 1932 by Clarke and Hoshall in the Journal of Biological Photography, where a two-dimensional image incorporated into a film was physically moved to create the illusion of motion. ${ }^{23,34}$ Later, the advent of photography gave birth to cell animation, where hand-drawn images are photographed and sequenced frame by frame, creating an animated film (https://en.wikipedia.org/w/index.php?title=Medical_ animation\&oldid=946202838). In 1960, William Fetter created the first computer-generated illustration of the human form, later developing it into a 3D image, which paved the way for computer-generated 3D medical animation. ${ }^{35}$ However, it was not until 1975 that the first medical animation was published in the journal Science, which demonstrated a complex intracellular molecular process. ${ }^{36}$ Since then, there has been enormous growth in the medical animation industry, which today accounts for an annual revenue of $\$ 15$ billion. ${ }^{23}$ With the availability of computerized 3D models, 3D digitizing arms, and scanners, 3D printing technology has evolved. It has varied applications from learning neuroanatomy to presurgical planning and training of surgeons. Interested bibliophiles are encouraged to review the paper by Pucci et al. ${ }^{37}$

\section{Simulation, Virtual Reality, and Augmented Reality}

Simulation is the "imitation of some real thing, state of affairs, or process." Although it began as a military tool to develop strategy, problem-solving, and decision-making skills, it ultimately made its way into the medical field. In the latter half of the 20th century, manikins were used as a simulation to teach medical skills like resuscitation and suturing. A cardiopulmonary resuscitation manikin called "Resusci Anne" was developed to teach mouth-tomouth breathing, ${ }^{38,39}$ and in the 1960 s, the first computer-controlled manikin, Sim One, simulated a real human look and possessed many physiological responses such as reacting to administered drugs. ${ }^{39}$ In 2012, ROWENA
(Realistic Operative Workstation for Educating Neurosurgical Apprentices), an anatomical simulator developed in the United Kingdom, realistically simulated all the layers of the head to allow training on neurosurgical procedures and craniotomy. ${ }^{40}$ Later, procedural simulators for critical care, craniotomy, ventriculostomy, spinal and vascular surgery, and endoscopy were developed for surgical training and education. ${ }^{39}$

Augmented reality (AR) and VR are modern technologies often used in conjunction with robotic surgery. While $\mathrm{AR}$ is used for perception enhancement, VR along with robotics is used to simulate the surgical environment to enhance learning. "VR" was a term coined by computer scientist Jaron Lanier who described it as "a collection of technologies that allow people to interact efficiently with $3 \mathrm{D}$ computerized databases in real time using their natural senses and skills." ${ }^{+42}$ The earliest virtual reality product was the Sensorama Simulator constructed by American cinematographer and inventor Morton Heilig in 1962. In 2007, VR and simulation were integrated into a robotic surgical system. Nowadays, many VR interfaces are key tools for teaching neuroanatomy, neurosurgical training, and quantifying surgeons' manual dexterity and competency. ${ }^{39} \mathrm{AR}$ in the neurosurgical field has progressed so rapidly in the last 2 decades, and the details of its history are beyond the scope of this review. Alaraj's Comprehensive Healthcare Simulation: Neurosurgery provides an extensive account of the topic. ${ }^{39}$

\section{Connecting the Dots}

Imagine writing a book or a paper like our predecessors did 2000 years ago. Taking on such a project would have been someone's whole life's work. As we glimpse through the evolution of mediums of dissemination, it is evident how much progress we have made and where we are heading. We are probably in one of those transitions noted throughout history, but this time the book is at the brink of extinction. Contemplating history, it is obvious that the future is the digital book. Though it offers the convenience of carrying an entire library with you, how safe is it? Are we prepared to rely on the privacy and security of cloud platforms? Can we store this exponentially increasing knowledge on a physical medium? Only the future holds the answers.

\section{Conclusions}

The knowledge of a civilization can exist for only as long as the surviving documentation of that knowledge. Any evidence of the abilities harbored by a civilization is limited by the structural integrity of the mediums with which it is recorded. As humanity made leaps in development, so did the opportunity to build upon that which had already been created. This technological revolution paved the way for the exponential growth of medical literature, and it allows us to continue to advance, building upon the gifts given to us by our predecessors.

\section{References}

1. Thorwald J. Science and Secrets of Early Medicine: Egypt, 
Mesopotamia, India, China, Mexico, Peru. Thames \& Hudson; 1962.

2. Senthilkumar SA, Rai B, Gunasekaran A. Big Data in healthcare management: a review of literature. Am J Theor Appl Bus. 2018;4(2):57-69.

3. Parker S. Kill or Cure: An Illustrated History of Medicine. DK; 2013.

4. Aminoff MJ, Boller F, Swaab DF, eds. Handbook of Clinical Neurology. Vol 95. Elsevier; 2009.

5. Mark JJ. Egyptian papyrus. Ancient History Encyclopedia. Accessed August 13, 2020. https://member.ancient.eu/ Egyptian_Papyrus

6. Haas LF. Papyrus of Ebers and Smith. J Neurol Neurosurg Psychiatry. 1999;67(5):578.

7. Hughes JT. The Edwin Smith Surgical Papyrus: an analysis of the first case reports of spinal cord injuries. Paraplegia. 1988;26(2):71-82.

8. Iniesta I. Hippocratic corpus. BMJ. 2011;342:d688.

9. Pearce JMS. Early contribution of Alexandria medical school to the anatomy, physiology and pathology of the nervous system. Rev Neurol (Paris). 2019;175(3):119-125.

10. Goedvriend GJM. Papermaking past and present. Endeavour 1988;12(1):38-43.

11. Tubbs RI, Gonzales J, Iwanaga J, et al. The influence of ancient Greek thought on fifteenth century anatomy: Galenic influence and Leonardo da Vinci. Childs Nerv Syst. 2018; 34(6):1095-1101.

12. Gurunluoglu R, Gurunluoglu A, Williams SA, Cavdar S. The history and illustration of anatomy in the Middle Ages. $J$ Med Biogr. 2013;21(4):219-229.

13. Calkins CM, Franciosi JP, Kolesari GL. Human anatomical science and illustration: the origin of two inseparable disciplines. Clin Anat. 1999;12(2):120-129.

14. Childress D. Johannes Gutenberg and the Printing Press. Twenty-First Century Books; 2008.

15. Hind AM. History of Engraving and Etching. Dover Publications; 2011.

16. Smith SB. From Ars to Scientia: the revolution of anatomic illustration. Clin Anat. 2006;19(4):382-388.

17. Ganseman Y, Broos P. Leonardo da Vinci and Andreas Vesalius; the shoulder girdle and the spine, a comparison. Acta Chir Belg. 2008;108(4):477-483.

18. Donaldson IM. Jacopo Berengario da Carpi: the first anatomy book with a complete series of illustrations. $J R$ Coll Physicians Edinb. 2008;38(4):375.

19. Russell GA. Vesalius and the emergence of veridical representation in Renaissance anatomy. Prog Brain Res. 2013;203: 3-32.

20. Sakai T. Historical evolution of anatomical terminology from ancient to modern. Anat Sci Int. 2007;82(2):65-81.

21. Lanska DJ, Lanska JR. Medieval and Renaissance anatomists: the printing and unauthorized copying of illustrations, and the dissemination of ideas. Prog Brain Res. 2013;203: 33-74.

22. Lithography. Encyclopedia Britannica. Accessed August 13, 2020. https://www.britannica.com/technology/lithography

23. A history of medical animation and scientific storytelling. Accessed August 13, 2020. https://random42.com/a-historyof-scientific-storytelling

24. Patel SK, Couldwell WT, Liu JK. Max Brödel: his art, legacy, and contributions to neurosurgery through medical illustration. J Neurosurg. 2011;115(1):182-190.

25. Ballestriero R. Anatomical models and wax Venuses: art masterpieces or scientific craft works? J Anat. 2010;216(2): 223-234.

26. Ortug A, Yuzbasioglu N. Tracing the papier mache anatomical models of Ottoman Turkish medicine and Louis Thomas Jerôme Auzoux. Surg Radiol Anat. 2019;41(10):1147-1154.
27. Davenport A. The History of Photography: An Overview. University of New Mexico Press; 1999.

28. Diamantis A, Magiorkinis E, Androutsos G. Alfred Francois Donné (1801-78): a pioneer of microscopy, microbiology and haematology. J Med Biogr. 2009;17(2):81-87.

29. Olvido KC. Reenactment, Reconstruction, Recovery: Nineteenth-Century Photographs in the History of Surgery. University of California; 2017.

30. Harvey Cushing/John Hay Whitney Medical Library. Accessed August 13, 2020. https://library.medicine.yale.edu

31. Wahl CJ, Tubbs RS, Spencer DD, Cohen-Gadol AA. Harvey Cushing as a book collector, bibliophile, and archivist: the precedence for the genesis of the Brain Tumor Registry. Historical vignette. J Neurosurg. 2009;111(5):1091-1095.

32. Updegraff HL. The rise of the surgical motion picture. Am J Surg. 1940;48(3):523-524.

33. Whiteley W. J. Rudolph Jaeger. Accessed August 13, 2020. http://www.mecfilms.com/rudolph.htm

34. Clarke CD, Hoshall EM. Illustration: Its Technique and Application to the Sciences. John D Lucas Co; 1939.

35. Weiner DD. Computer animation-an exciting new tool for educators. IEEE Trans Educ. 1971;14(4):202-209.

36. Collins DM, Cotton FA, Hazen EE Jr, et al. Protein crystal structures: quicker, cheaper approaches. Science. 1975; 190(4219):1047-1053.

37. Pucci JU, Christophe BR, Sisti JA, Connolly ES Jr. Threedimensional printing: technologies, applications, and limitations in neurosurgery. Biotechnol Adv. 2017;35(5):521-529.

38. Rosen KR. The history of medical simulation. J Crit Care. 2008;23(2):157-166.

39. Alaraj A. Comprehensive Healthcare Simulation: Neurosurgery. Springer International Publishing; 2018.

40. Ashpole R. Introducing Rowena: a simulator for neurosurgical training. Bull R Coll Surg Engl. 2015;97(7):299-301.

41. Ferro M, Brunori D, Magistri F, et al. A portable da Vinci simulator in virtual reality. Paper presented at: Third IEEE International Conference on Robotic Computing (IRC); February 25-27, 2019; Naples, Italy.

42. Albani JM, Lee DI. Virtual reality-assisted robotic surgery simulation. J Endourol. 2007;21(3):285-287.

\section{Disclosures}

The authors report no conflict of interest concerning the materials or methods used in this study of the findings specified in this paper.

\section{Author Contributions}

Conception and design: Raju. Acquisition of data: Raju. Drafting the article: Raju, Jumah, Sonig. Critically revising the article: Jumah, Sun. Reviewed submitted version of manuscript: Nanda, Raju, Jumah, Narayan, Sonig. Administrative/technical/material support: Narayan. Study supervision: Nanda, Sun.

\section{Supplemental Information \\ Previous Presentations}

Portions of this paper were presented at the AANS Virtual 2020 E-Poster Hall.

\section{Correspondence}

Anil Nanda: Rutgers-Robert Wood Johnson Medical School, New Brunswick; Rutgers New Jersey Medical School, Newark, NJ. an651@rwjms.rutgers.edu. 